\title{
PRODUÇÃO DE CONCENTRADOS DE ÁCIDOS GRAXOS POR HIDRÓLISE DE ÓLEOS VEGETAIS MEDIADA
} POR LIPASE VEGETAL

\author{
Adriane D. Coelho, Kádima C. Santos, Rui C. C. Domingues e Adriano A. Mendes* \\ Universidade Federal de São João Del Rei, CP 56, 35701-970 Sete Lagoas - MG, Brasil
}

Recebido em 16/1/13; aceito em 8/5/13; publicado na web em 10/6/13

\begin{abstract}
PRODUCTION OF CONCENTRATED FATTY ACIDS BY HYDROLYSIS OF VEGETABLE OILS CATALYZED BY PLANT LIPASE. The aim of this work was to verify the ability of enzymatic crude extract from dormant castor bean seeds to yield concentrated fatty acids by hydrolysis of polyunsaturated vegetable oils such as corn and sunflower. The enzymatic extract exhibited higher activity towards corn oil, which was selected for further studies to determine optimum hydrolysis conditions by factorial design. Maximum hydrolysis percentage $(\approx 84 \%)$ was reached at $60 \%$ wt. oil:buffer acetate $100 \mathrm{mM} \mathrm{pH} 4.5,33{ }^{\circ} \mathrm{C}$ and $5.0 \%$ wt. of crude extract after $70 \mathrm{~min}$ of reaction. These results suggest that the use of low-cost lipase from castor bean seeds has potential for oil hydrolysis.
\end{abstract}

Keywords: oil hydrolysis; factorial design; plant lipase.

\section{INTRODUÇÃO}

A produção mundial de óleos e gorduras tem crescido nos últimos anos. Em 2008/2009, cerca de 162,7 milhões de toneladas foram geradas, comparadas a 150 e 154 milhões de toneladas em 2006 e 2007 , respectivamente. ${ }^{1-3}$ Estes números referem-se apenas à produção dos principais óleos e gorduras como soja, algodão, amendoim, girassol, colza, gergelim, milho, oliva, palma, coco, linhaça e mamona, e as gorduras de fonte animal como manteiga, sebo e peixe. ${ }^{3}$

A modificação química destes óleos e gorduras mediada por catalisadores químicos é normalmente realizada em elevadas temperaturas e pressão $\left(250{ }^{\circ} \mathrm{C}\right.$ e $\left.50 \mathrm{~atm}\right)$. Geralmente, estes processos fornecem produtos de composição química mista e/ou contaminada devido à ocorrência de reações indesejáveis como oxidação, desidratação e interesterificação que requerem etapas posteriores de purificação. Neste contexto, a modificação de óleos e gorduras catalisada por lipases vem se apresentando como uma alternativa atrativa para a indústria, principalmente quando são consideradas algumas das vantagens desta rota como maior rendimento do processo, menor consumo de energia, redução do teor de resíduos e introdução de rotas mais acessíveis de produção. ${ }^{4-10}$

Lipases (glicerol éster hidrolases - E.C. 3.1.1.3) são enzimas que catalisam a hidrólise de ligações éster de óleos e gorduras com diferentes especificidades e podem, em meio orgânico, catalisar uma variedade de reações, como esterificação, interesterificação, transesterificação e aminólise. As lipases têm sido amplamente empregadas na produção de fármacos, emulsificantes, alimentos, perfumaria, diagnósticos médicos, compostos opticamente ativos, polímeros, aromas e fragrâncias, modificações de lipídeos para a produção de biodiesel e lipídeos estruturados e no pré-tratamento de efluentes com elevado teor de lipídeos gerados pelas indústrias de alimentos. ${ }^{11-15}$

Essas enzimas encontram-se largamente distribuídas na natureza em tecidos animais e vegetais e biomassa microbiana. ${ }^{11-16}$ Dentre elas, as lipases microbianas são as mais utilizadas industrialmente. ${ }^{6,12,13}$ Por outro lado, as lipases vegetais apresentam algumas vantagens em relação às lipases microbianas e animais como ampla disponibilidade, baixo custo e elevada especificidade. ${ }^{14-16}$ As principais fontes de lipases vegetais são o látex de frutos do gênero Carica como babaco e

*e-mail: adriano_amendes@yahoo.com.br mamão e sementes de oleaginosas e cereais. ${ }^{14-23}$ Trabalhos reportados pela literatura especializada mostram o aumento da atividade catalítica de hidrolases, incluindo lipases, durante o processo de germinação de sementes. ${ }^{14-19}$ Os materiais de reserva presentes nas sementes como amido, proteínas e/ou lipídeos são hidrolisados por ação de hidrolases produzidas durante o processo de germinação tais como proteases, amilases e lipases para fornecer energia e componentes para o crescimento embrionário nos primeiros estágios de desenvolvimento. ${ }^{16,17,24}$ Óleos e gorduras são convertidos em ácidos graxos livres que posteriormente são convertidos em açúcares por reações de $\beta$-oxidação. ${ }^{24,25}$ Entretanto, a atividade lipásica também pode ser detectada em sementes dormentes de algumas oleaginosas como mamona e pinhão-manso. ${ }^{21-24} \mathrm{~A}$ aplicação de extratos brutos obtidos de sementes dormentes com elevada atividade lipásica é bastante atrativa, pois não são requeridas etapas de germinação e, consequentemente, reduz os custos de obtenção destes biocatalisadores. Além disso, os óleos são consumidos durante o processo de germinação e a utilização de sementes dormentes permite maior rendimento de extração, o que é atrativo para o setor oleoquímico. ${ }^{19}$

O objetivo do presente trabalho consiste na aplicação de extrato enzimático de baixo custo obtido de sementes dormentes de mamona para a produção de concentrados de ácidos graxos por hidrólise de óleos vegetais na ausência de emulsificantes. Estes concentrados de ácidos graxos são de grande interesse para o setor industrial para a obtenção de materiais para revestimentos, adesivos, biocombustíveis, surfactantes, lubrificantes e produtos de higiene pessoal. ${ }^{5,21,22}$

\section{PARTE EXPERIMENTAL}

\section{Materiais}

Sementes de mamona foram adquiridas da empresa BRSeed Produção e Comércio de Sementes (Araçatuba/SP). Óleos vegetais de baixa acidez como azeite de oliva (Carbonell) e girassol e milho (Liza) foram adquiridos no comércio local. Goma arábica foi adquirida da Synth (São Paulo/SP). Hidróxido de sódio (pureza > 99\%) foi adquirido da Vetec (São Paulo/SP). Acetato de sódio e ácido acético (pureza > 99\%) e fosfato de sódio monobásico e bibásico (pureza $>98 \%$ ) foram adquiridos da Synth (São Paulo/SP). Todos os outros reagentes empregados foram de grau analítico. 


\section{Métodos}

Preparação do extrato bruto de lipase de sementes de mamona

Inicialmente, os endospermas das sementes foram removidos e as cascas descartadas. Os endospermas $(20 \mathrm{~g})$ foram triturados em moinho de facas por um período de $10 \mathrm{~min}$ com a adição de acetona a frio (5 $\mathrm{mL}$ ). Após a trituração, o extrato foi mantido sob suave agitação mecânica $(150 \mathrm{rpm})$ na presença de acetona a frio (relação extrato:solvente 1:5) por 10-15 min, conforme metodologia descrita por Avelar et al..$^{22}$ A suspensão foi filtrada a vácuo em um funil de Buchner e lavada com acetona a frio em excesso. $\mathrm{O}$ tamanho das partículas do extrato bruto obtido foi classificado em sistemas de peneiras e foram empregadas as partículas com diâmetro entre 75-90 $\mu \mathrm{m}$. O extrato enzimático bruto das sementes de mamona obtido foi empregado como biocatalisador nas reações de hidrólise dos óleos vegetais.

\section{Determinação da atividade hidrolítica na hidrólise de diferentes óleos vegetais}

A atividade hidrolítica do extrato enzimático bruto preparado a partir de sementes dormentes de mamona foi determinada pelo método de hidrólise da emulsão de óleos vegetais (girassol, milho e oliva), conforme metodologia adaptada de Soares et al. ${ }^{26} \mathrm{~A}$ solução de substrato foi preparada pela emulsão de $25 \mathrm{~g}$ de óleo vegetal e $75 \mathrm{~g}$ de solução de goma arábica a $3 \% \mathrm{~m} / \mathrm{m}$. Em frascos Erlenmeyer de $125 \mathrm{~mL}$ foram adicionados $5 \mathrm{~mL}$ da solução de substrato, $5 \mathrm{~mL}$ de solução tampão fosfato de sódio $(100 \mathrm{mM}, \mathrm{pH} 7,0)$ e adicionado $0,1 \mathrm{~g}$ de extrato enzimático bruto. Os frascos foram incubados a $37^{\circ} \mathrm{C}$ por $5 \mathrm{~min}$, em banho termostatizado com agitação de $200 \mathrm{rpm}$. A reação foi finalizada pela adição de $10 \mathrm{~mL}$ de etanol comercial $(92,5 \%$ em massa) e os ácidos graxos liberados quantificados por titulação com solução de $\mathrm{NaOH} 20 \mathrm{mM}$, empregando fenolftaleína como indicador. Uma unidade de atividade foi definida como a quantidade de enzima que libera $1 \mu \mathrm{mol}$ de ácido graxo por minuto de reação, nas condições do ensaio. ${ }^{22}$

\section{Delineamento experimental para a hidrólise do óleo de milho}

Para a hidrólise do óleo de milho, foi proposto um delineamento experimental $2^{3}$ composto rotacional com 17 ensaios ( 8 fatoriais, 6 axiais e 3 pontos centrais) para melhor entendimento da influência individual das variáveis estudadas e de suas interações na reação de hidrólise. Os parâmetros avaliados foram a relação mássica óleo:tampão $\left(\mathrm{x}_{1}\right)$, temperatura $\left(\mathrm{x}_{2}\right)$ e concentração de tampão $\left(\mathrm{x}_{3}\right)$. Os valores codificados e não codificados correspondentes são mostrados na Tabela 1. Como variável resposta foi considerada a porcentagem de hidrólise. Os resultados obtidos foram analisados empregando o software Statistica versão 7.0 (StatSoft Inc., EUA).

As reações de hidrólise foram conduzidas em regime batelada em frascos de $250 \mathrm{~mL}$ contendo $50 \mathrm{~g}$ do sistema reacional (óleo + tampão acetato de sódio $\mathrm{pH} 4,5)$ e concentração fixa de enzima ( $2 \%$ em massa de extrato enzimático bruto). Os meios reacionais foram incubados sob agitação mecânica de $1000 \mathrm{rpm}$ por um período de $30 \mathrm{~min}$. A porcentagem de hidrólise, definida pela relação entre a concentração de ácidos graxos livres presentes na amostra e a concentração máxima teórica, foi determinada de acordo com a Equação $1{ }^{4}$

$$
\text { Hidrólise }(\%)=\frac{V \times 10^{-3} \times M \times M M}{m \times f} \times 100
$$

na qual: $\mathrm{V}$ é o volume de solução de $\mathrm{NaOH}$ consumido na titulação; M é a concentração molar da solução de $\mathrm{NaOH}$ (20 mM); MM é a massa molecular média dos ácidos graxos do óleo de milho $(280,22$ $\mathrm{g} / \mathrm{mol}$ ); m é a massa da amostra (g) e f é a fração de óleo na solução de substrato.
Tabela 1. Planejamento experimental para a hidrólise do óleo de milho catalisada por lipase de sementes dormentes de mamona em reator batelada. Condições reacionais: $50 \mathrm{~g}$ de substrato, $2 \%$ em massa de extrato enzimático bruto, tampão acetato de sódio pH 4,5, 1000 rpm por 30 min de reação

\begin{tabular}{ccccc}
\hline & \multicolumn{3}{c}{ Variáveis codificadas (originais) } & \\
\cline { 2 - 4 } Ensaios & $\begin{array}{c}\text { Razão mássica } \\
\text { óleo:tampão } \\
\text { (\% em massa) }\end{array}$ & $\begin{array}{c}\text { Temperatura } \\
\left({ }^{\circ} \mathrm{C}\right)\end{array}$ & $\begin{array}{c}\text { Concentração } \\
\text { de tampão } \\
(\mathrm{mM})\end{array}$ & \\
\hline $\mathbf{1}$ & $-1(32)$ & $-1(31)$ & $-1(20)$ & $1,1 \pm 0,2$ \\
$\mathbf{2}$ & $+1(48)$ & $-1(31)$ & $-1(20)$ & $0,4 \pm 0,1$ \\
$\mathbf{3}$ & $-1(32)$ & $+1(49)$ & $-1(20)$ & $1,6 \pm 0,1$ \\
$\mathbf{4}$ & $+1(48)$ & $+1(49)$ & $-1(20)$ & $0,40 \pm 0$ \\
$\mathbf{5}$ & $-1(32)$ & $-1(31)$ & $+1(80)$ & $29,9 \pm 0,1$ \\
$\mathbf{6}$ & $+1(48)$ & $-1(31)$ & $+1(80)$ & $33,3 \pm 0,7$ \\
$\mathbf{7}$ & $-1(32)$ & $+1(49)$ & $+1(80)$ & $25,7 \pm 0,3$ \\
$\mathbf{8}$ & $+1(48)$ & $+1(49)$ & $+1(80)$ & $30,4 \pm 1,4$ \\
$\mathbf{9}$ & $-1,68(20)$ & $0(40)$ & $0(50)$ & $24,3 \pm 0,7$ \\
$\mathbf{1 0}$ & $+1,68(60)$ & $0(40)$ & $0(50)$ & $32,7 \pm 2,1$ \\
$\mathbf{1 1}$ & $0(40)$ & $-1,68(25)$ & $0(50)$ & $22,6 \pm 0,9$ \\
$\mathbf{1 2}$ & $0(40)$ & $+1,68(55)$ & $0(50)$ & $8,2 \pm 0,3$ \\
$\mathbf{1 3}$ & $0(40)$ & $0(40)$ & $-1,68(0)$ & $0,2 \pm 0$ \\
$\mathbf{1 4}$ & $0(40)$ & $0(40)$ & $+1,68(100)$ & $38,1 \pm 1,1$ \\
$\mathbf{1 5}$ & $0(40)$ & $0(40)$ & $0(50)$ & $29,6 \pm 0,8$ \\
$\mathbf{1 6}$ & $0(40)$ & $0(40)$ & $0(50)$ & $28,8 \pm 0,5$ \\
$\mathbf{1 7}$ & $0(40)$ & $0(40)$ & $0(50)$ & $29,6 \pm 0,4$ \\
\hline
\end{tabular}

Otimização da hidrólise enzimática de óleos vegetais

Após a seleção das condições experimentais que maximizam o processo de hidrólise determinadas pelo delineamento experimental, foram realizados ensaios de hidrólise do óleo de milho variando a razão mássica óleo:tampão acetato de sódio $(100 \mathrm{mM}, \mathrm{pH} 4,5)$ de 60 a $85 \%$ e concentração de tampão $(100-200 \mathrm{mM})$. O efeito da concentração de extrato bruto na porcentagem de hidrólise também foi estudado no intervalo de 1 a $6 \%$ em massa. Em condições otimizadas, a hidrólise dos óleos de milho e girassol foi conduzida para determinar a máxima porcentagem de hidrólise. Estas reações foram realizadas em frascos de $250 \mathrm{~mL}$ contendo $50 \mathrm{~g}$ de substrato $(60 \%$ em massa de óleo vegetal + tampão acetato de sódio 100 mM pH 4,5) e $5 \%$ em massa de extrato enzimático bruto sob agitação vigorosa (1000 rpm) a $33^{\circ} \mathrm{C}$.

\section{RESULTADOS E DISCUSSÃO}

Inicialmente, foi determinada a atividade hidrolítica do extrato enzimático bruto empregando emulsões dos diferentes óleos vegetais. O óleo vegetal que apresentou maior atividade hidrolítica foi selecionado e as condições que maximizam o processo de hidrólise tais como razão mássica óleo:tampão acetato de sódio pH 4,5, temperatura de reação e concentração do tampão foram avaliadas por delineamento experimental completo composto rotacional. Após a seleção das variáveis que afetam significativamente a reação de hidrólise, foi verificada a influência da concentração de enzima na porcentagem de hidrólise.

A atividade catalítica do extrato enzimático bruto foi determinada na hidrólise de óleos vegetais emulsificados com goma arábica. Dentre os óleos testados, máxima atividade catalítica foi obtida na hidrólise do óleo de milho (156,2 \pm 9,4 UI/g), seguido de óleo de girassol (126,1 $\pm 7,6 \mathrm{UI} / \mathrm{g})$ e oliva $(61,1 \pm 4,5 \mathrm{UI} / \mathrm{g})$. De acordo com estes resultados, verifica-se que a lipase de mamona foi mais ativa na hidrólise de óleos vegetais com elevada concentração de ácidos graxos poli-insaturados em sua composição como girassol e milho. ${ }^{27}$ 
Estes resultados corroboram com aqueles obtidos na hidrólise dos óleos de canola, soja e oliva catalisada pelo extrato bruto de sementes dormentes de mamona na qual foi observada maior atividade catalítica para os óleos vegetais contendo elevada concentração de ácidos graxos poli-insaturados como canola e soja. ${ }^{22}$

Com base nestes resultados, o óleo de milho foi selecionado para a produção de concentrados de ácidos graxos por hidrólise em reator batelada. As reações foram conduzidas em pH 4,5, pH ótimo de atuação da lipase de mamona, ${ }^{22-24}$ e na ausência de emulsificantes. As reações de hidrólise de óleos e gorduras mediada por lipases de diferentes fontes têm sido realizadas na presença de emulsificantes para aumentar a área interfacial óleo/água que, por sua vez, aumenta a atividade catalítica da enzima. ${ }^{28}$ Neste trabalho, a emulsificação do meio reacional foi obtida por agitação mecânica vigorosa (1000 rpm). Em escala industrial, a hidrólise de óleos e gorduras realizada sem a adição de agentes emulsionantes é economicamente mais atrativa porque reduz os custos do processo e permite fácil separação do produto de interesse (concentrados de ácidos graxos). ${ }^{22}$

As condições que maximizam a porcentagem de hidrólise do óleo foram determinadas por delineamento experimental completo composto rotacional e os parâmetros avaliados foram a relação mássica óleo:tampão (20-60\% em massa de óleo), temperatura $\left(25-55^{\circ} \mathrm{C}\right)$ e concentração de tampão $(0-100 \mathrm{mM})$. Os resultados obtidos no delineamento experimental para a avaliação do efeito das variáveis estudadas na porcentagem de hidrólise do óleo de milho estão ilustrados na Tabela 1. As estimativas dos efeitos, erros-padrão e do valor de $p$ para as respostas analisadas são apresentadas na Tabela 2.

Tabela 2. Estimativas dos efeitos das variáveis, erros padrão e valores de $p$ para o delineamento experimental composto rotacional

\begin{tabular}{cccc}
\hline Variáveis & Efeitos & Erro Padrão & $p$ \\
\hline Média & 28,5739 & $\pm 2,8579$ & 0,0000 \\
$\mathrm{x}_{1}$ & 2,6537 & $\pm 2,2061$ & 0,2681 \\
$\mathrm{x}_{1}{ }^{2}$ & $-0,5097$ & $\pm 1,4538$ & 0,7362 \\
$\mathrm{x}_{2}$ & $-4,5148$ & $\pm 2,7130$ & 0.1400 \\
$\mathrm{x}_{2}{ }^{2}$ & $-11,9458$ & $\pm 3,1376$ & 0,0066 \\
$\mathrm{x}_{3}$ & 26,4049 & $\pm 2,7130$ & 0,0000 \\
$\mathrm{x}_{3}{ }^{2}$ & $-9,5428$ & $\pm 3,1376$ & 0,0215 \\
$\mathrm{x}_{1} \cdot \mathrm{x}_{2}$ & 0,2000 & $\pm 3,5315$ & 0,9564 \\
$\mathrm{x}_{1} \cdot \mathrm{x}_{3}$ & 2,500 & $\pm 3,5315$ & 0,5019 \\
$\mathrm{x}_{2} \cdot \mathrm{x}_{3}$ & $-1,900$ & $\pm 3,5315$ & 0,6072 \\
\hline
\end{tabular}

De acordo com os dados apresentados na Tabela 1, a porcentagem de hidrólise do óleo de milho variou entre $0,2 \pm 0$ e 38,1 $\pm 1,1 \%$. Estes valores correspondem aos ensaios conduzidos respectivamente com mínima e máxima concentração de tampão acetato de sódio (ensaios 13 e 14). Na Tabela 2, verifica-se que para a variável concentração do tampão $\left(\mathrm{x}_{3}\right)$ tanto o termo linear como o quadrático apresentaram influência significativa ao nível de $95 \%$ de confiança. No entanto, para a variável temperatura $\left(\mathrm{x}_{2}\right)$ apenas o termo quadrático foi significativo estatisticamente. Os termos linear e quadrático da razão mássica óleo:tampão e o termo linear da temperatura, bem como as interações entre as variáveis estudadas, não foram estatisticamente significativos $(p>0,05)$. A partir dos resultados sumarizados na Tabela 2 foi possível compor o modelo estatístico incluindo os coeficientes correspondentes aos efeitos significativos, conforme apresentados na Equação 2. Os coeficientes relativos aos efeitos não significativos foram excluídos do modelo.
Hidrólise $(\%)=28,57-5,97 x_{2}^{2}+13,20 x_{3}-4,62 x_{3}^{2}$ $\mathrm{R}^{2}=0,9453$

na qual: $x_{2}$ é o valor codificado da variável temperatura e $x_{3}$ é o valor codificado da variável concentração do tampão.

O teste de significância para o modelo estatístico foi avaliado pelo teste $\mathrm{F}$, revelando que a regressão foi significativa ao nível de $95 \%$ de confiança (Tabela 3). O modelo não apresentou falta de ajuste e a determinação do coeficiente de correlação $\left(\mathrm{R}^{2}=0,9452\right)$ mostra que $94,5 \%$ da variabilidade na resposta, em relação à análise dos resultados, pode ser explicada pelo modelo. Desta forma, considerou-se que o modelo estatístico obtido foi adequado para a descrição da porcentagem do óleo de milho em função das variáveis avaliadas (relação mássica óleo:tampão, temperatura e concentração de tampão), obtendo-se as superfícies de resposta apresentadas na Figura 1(a,b,c).

Tabela 3. Análise de variância (ANOVA) para o ajuste do modelo proposto que representa a porcentagem de hidrólise do óleo de milho

\begin{tabular}{cccccc}
\hline Fonte & $\begin{array}{c}\text { Soma } \\
\text { quadrática }\end{array}$ & $\begin{array}{c}\text { Grau de } \\
\text { liberdade }\end{array}$ & $\begin{array}{c}\text { Média } \\
\text { quadrática }\end{array}$ & $\mathrm{F}$ & $\mathrm{p}$ \\
\hline $\mathrm{x}_{2}{ }^{2}$ & 361,57 & 1 & 361,57 & 14,4955 & 0,0066 \\
$\mathrm{x}_{3}$ & 2362,80 & 1 & 2362,80 & 94,7253 & 0,0000 \\
$\mathrm{x}_{3}^{2}$ & 216,60 & 1 & 216,60 & 8,6834 & 0,0215 \\
$\begin{array}{c}\text { Falta de } \\
\text { ajuste }\end{array}$ & 128,03 & 6 & 21,338 & & \\
Erro puro & 174,61 & 7 & 24,944 & & \\
Cor total & 3186,26 & 16 & & & \\
\hline
\end{tabular}

A superfície de resposta referente ao efeito das variáveis razão mássica óleo:tampão e temperatura na porcentagem de hidrólise do óleo de milho é mostrada na Figura 1a. A porcentagem de hidrólise aumentou com o aumento da razão mássica óleo:tampão e com o aumento da temperatura. Em temperaturas superiores a $45{ }^{\circ} \mathrm{C}$ foi observada uma drástica redução da porcentagem de hidrólise devido à inativação da enzima em elevadas temperaturas. ${ }^{22} \mathrm{~A}$ faixa ótima da temperatura de hidrólise foi observada no intervalo de $33-45^{\circ} \mathrm{C}$. Os ensaios conduzidos em temperaturas inferiores a $30^{\circ} \mathrm{C}$ também reduziram a porcentagem de hidrólise do óleo de milho devido ao aumento da viscosidade da emulsão pela aglomeração das gotas de óleo, favorecida com a redução da temperatura. ${ }^{29}$ De acordo com a Figura 1a, elevada porcentagem de hidrólise pode ser alcançada com máxima razão mássica óleo:tampão $(60 \%)$ e temperatura variando entre $33-45^{\circ} \mathrm{C}$.

O efeito das variáveis razão mássica óleo:tampão e concentração de tampão na porcentagem de hidrólise é mostrada na Figura 1b. Nos níveis máximos de razão mássica óleo:tampão (60\%) e concentração de tampão acetato de sódio $(100 \mathrm{mM})$ foram obtidas as mais elevadas porcentagens de hidrólise. De acordo com os dados apresentados na Tabela 1, a porcentagem de hidrólise para as reações conduzidas em concentração de tampão inferior a $20 \mathrm{mM}$ foi inferior a $2 \%$ após 30 min de reação. Estes resultados podem ser também atribuídos à agregação de gotas de óleo para a formação de gotas maiores que reduz drasticamente a sua área superficial na interface óleo/água..$^{29,30}$ Em elevadas concentrações de óleo esta agregação é favorecida. Diferentes estratégias têm sido empregadas para evitar a agregação das gotas de óleo na interface óleo/água, tais como a adição de agentes emulsificantes, poliois, proteínas e sais. ${ }^{29,31,32}$ No entanto, neste estudo as reações foram conduzidas sem a adição destes compostos, portanto, elevada concentração de tampão foi requerida para evitar a agregação destas gotas de óleo devido à repulsão eletrostática entre elas. ${ }^{29}$ Sob estas condições, uma maior área superficial destas 

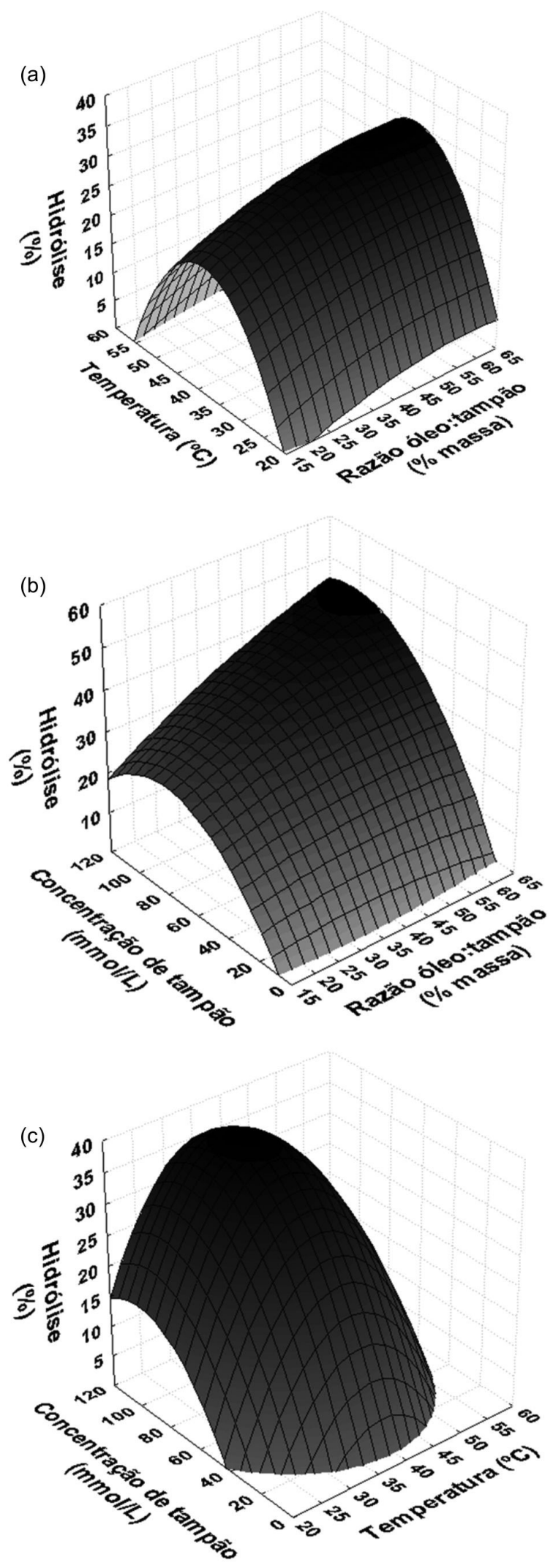

Figura 1. Superfícies de resposta de acordo com o modelo quadrático predito para a hidrólise enzimática do óleo de milho. Efeito da temperatura e razão mássica óleo:tampão (a); efeito da concentração de tampão e razão mássica óleo:tampão (b); e efeito da concentração de tampão e temperatura (c) na porcentagem de hidrólise do óleo de milho catalisada pela lipase de sementes dormentes dormentes de mamona gotículas pode ser obtida, permitindo uma melhor interação entre as moléculas de lipase e o substrato.

Na Figura 1c é mostrado o efeito das variáveis temperatura e concentração de tampão na porcentagem de hidrólise. A superfície de resposta mostra claramente que o aumento da concentração de tampão influenciou significatimente na porcentagem de hidrólise do óleo de milho. Com relação ao efeito da temperatura, foi possível verificar que a faixa ótima de atuação da enzima foi entre $33-45^{\circ} \mathrm{C}$, corroborando com os resultados mostrados na Figura 1a.

Conforme pode ser observado na Figura 1, os máximos valores de porcentagem de hidrólise do óleo de milho foram obtidos nos níveis máximos de concentração de tampão e razão mássica óleo:tampão. Deste modo, concentração de tampão e razão mássica óleo:tampão superiores aos níveis empregados no delineamento experimental foram testados para verificar as condições reacionais que maximizam a reação de hidrólise do óleo de milho e os resultados obtidos estão sumarizados na Figura 2a,b. A temperatura de reação selecionada foi de $33{ }^{\circ} \mathrm{C}$, temperatura mínima necessária para atingir máxima porcentagem de hidrólise, conforme mostrado nas superfícies de resposta de acordo com o modelo predito para a reação de hidrólise (Figura 1a,c). De acordo com a Figura 2a, máxima porcentagem de hidrólise foi obtida com razão mássica óleo:tampão de $60 \%$ em massa de óleo, nível máximo empregado no delineamento experimental. Em concentrações acima de $60 \%$ foi observada uma drástica redução da porcentagem de hidrólise devido à agregação das gotas de óleo com o aumento da concentração de óleo na emulsão que, eventualmente, resultou na redução da área de contato entre as moléculas de lipase e as gotas de óleo, como descrito anteriormente. ${ }^{29}$ Além disso, elevadas concentrações de óleo aumentam a concentração de ácidos graxos na interface óleo/água que promove mudanças do estado de ionização da enzima na qual afeta a sua atividade catalítica e seletividade. ${ }^{33} \mathrm{~A}$ variação da concentração de tampão de 100 para $200 \mathrm{mM}$ também foi verificada no processo de hidrólise do óleo, conforme mostrado na Figura 2b. Com o aumento da concentração de tampão é esperado um aumento da porcentagem da hidrólise devido à menor variação do $\mathrm{pH}$ no meio de reação e menor agregação das gotas de óleo., ${ }^{4,29}$ Entretanto, o aumento da concentração de tampão de 100 para 200 mM não aumentou significativamente a porcentagem de hidrólise, ou seja, concentração de tampão $100 \mathrm{mM}$ foi o suficiente para evitar esta agregação das gotas de óleo e variações de $\mathrm{pH}$ no meio de reação por influência dos ácidos graxos liberados pela reação de hidrólise. Com base nestes resultados, nos níveis máximos de razão mássica óleo:tampão (60\% em massa de óleo) e concentração de tampão acetato de sódio pH 4,5 (100 mM) foi alcançada máxima porcentagem de hidrólise do óleo de milho $(38,1 \pm 1,1 \%)$.

A influência da concentração de extrato enzimático bruto na reação de hidrólise foi avaliada na faixa de 1 a $6 \%$ em massa de extrato e os resultados são mostrados na Figura 3. Como pode ser observado, o aumento da concentração de enzima também aumentou a porcentagem de hidrólise do óleo e máxima porcentagem de hidrólise foi obtida na concentração de $5 \%$ de extrato bruto, 60,3 \pm $2,1 \%$ após 30 min de reação. Para a hidrólise catalisada com maior concentração de extrato bruto $(6,0 \%$ em massa) não foi verificado um aumento acentuado na percentagem de hidrólise porque as gotas de óleo podem encapsular as moléculas de lipase no seu interior que reduz a atividade catalítica do biocatalisador. ${ }^{30}$

De acordo com os resultados obtidos, máxima produção de concentrados de ácidos graxos pode ser obtida para as reações conduzidas a $33{ }^{\circ} \mathrm{C}$ em tampão acetato de sódio $\mathrm{pH}$ 4,5 (100 mM) contendo $60 \%$ em massa de óleo e $5 \%$ em massa de extrato bruto de sementes dormentes de mamona sob agitação vigorosa (1000 rpm). Sob estas condições, máxima porcentagem de hidrólise do óleo de milho $(84,0$ $\pm 1,8 \%$ ) foi obtida após 70 min de reação, conforme mostrado na 

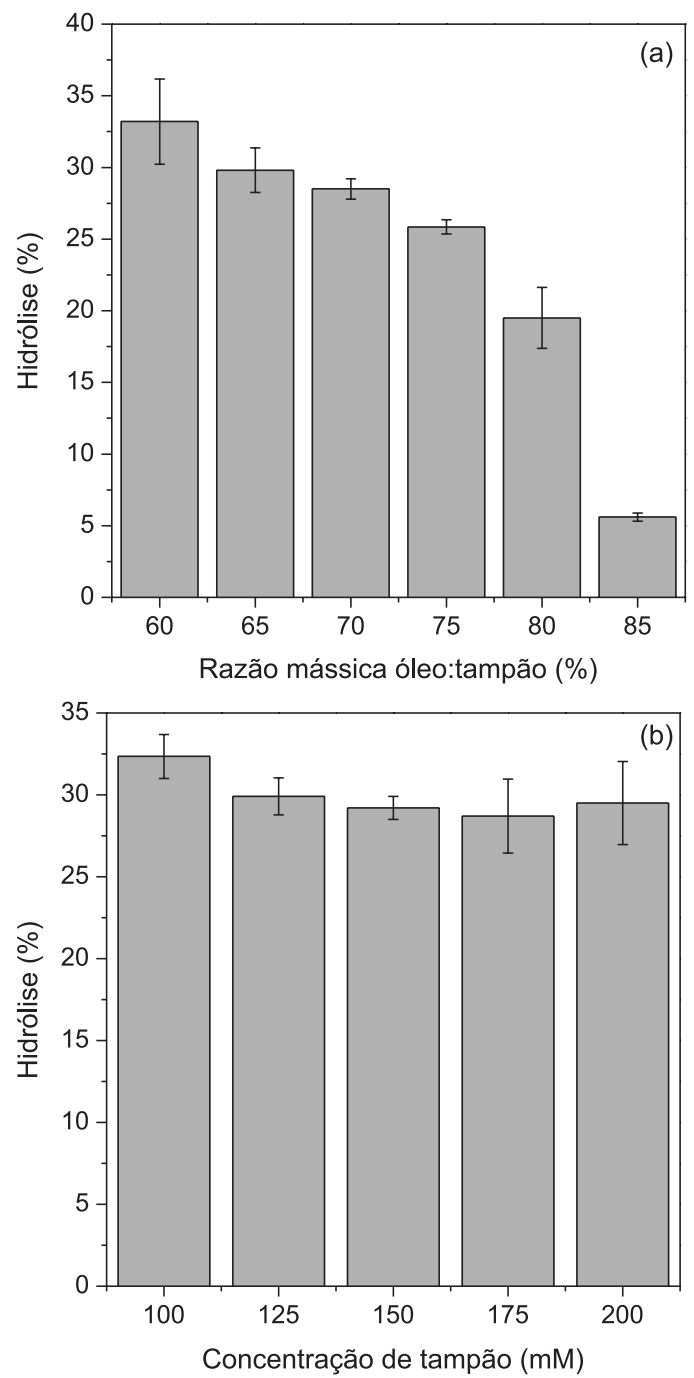

Figura 2. Influência da razão mássica óleo:tampão (a) e concentração de tampão (b) na porcentagem de hidrólise do óleo de milho. Condições reacionais: $33{ }^{\circ} \mathrm{C}, 30 \mathrm{~min}$, tampão acetato de sódio $\mathrm{pH} 4,5,2 \%$ de extrato enzimático bruto, $1000 \mathrm{rpm}$

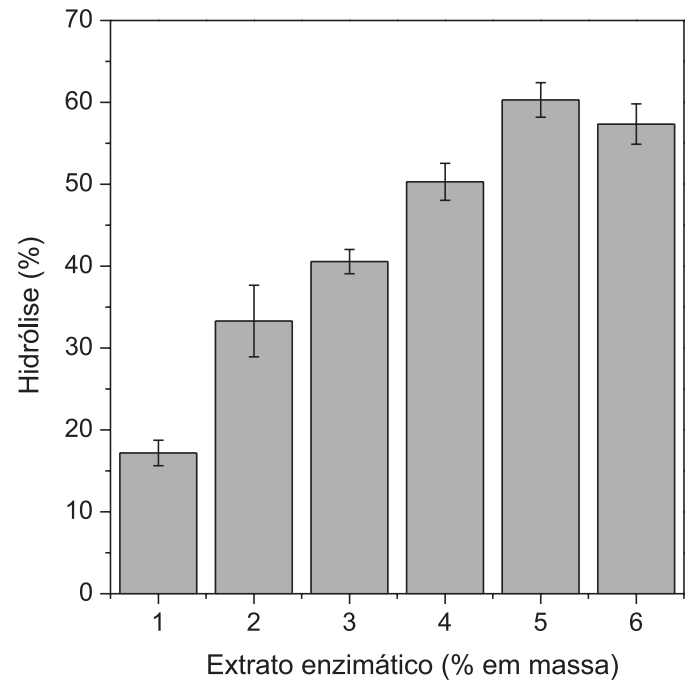

Figura 3. Influência da concentração de extrato enzimático de sementes dormentes de mamona na porcentagem de hidrólise do óleo de milho. Condições reacionais: $33^{\circ} \mathrm{C}, 30 \mathrm{~min}$, tampão acetato de sódio $100 \mathrm{mM} \mathrm{pH} \mathrm{4,5,60 \%} \mathrm{em}$ massa de óleo, $1000 \mathrm{rpm}$
Figura 4. O óleo de girassol também foi hidrolisado nas condições reacionais otimizadas para o óleo de milho e máxima porcentagem de hidrólise foi observada após 80 min de reação $(76,4 \pm 1,3 \%)$.

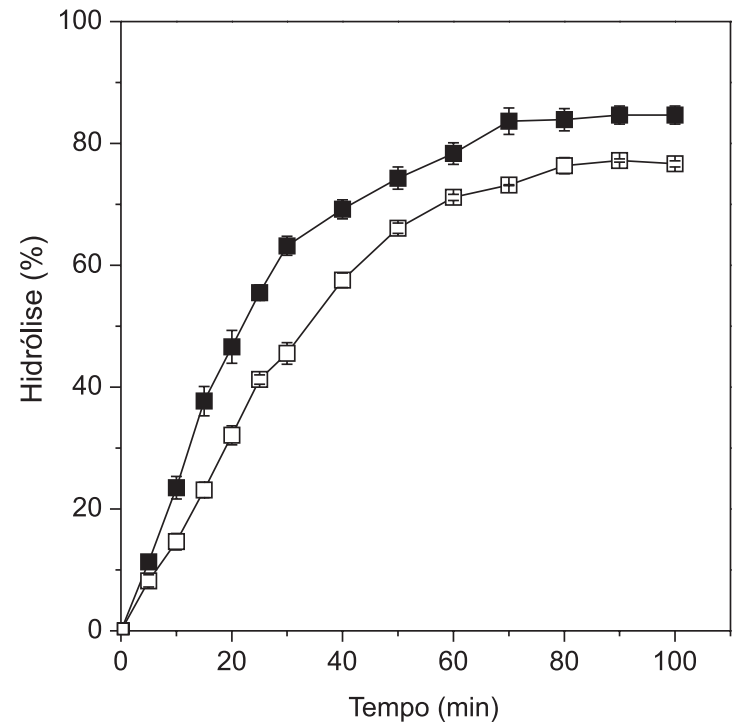

Figura 4. Perfil cinético de hidrólise dos óleos de milho (ロ) e girassol ( $\square)$ nas condições otimizadas pelo delineamento experimental. Condições reacionais: $33{ }^{\circ} \mathrm{C}$, tampão acetato de sódio $100 \mathrm{mM} \mathrm{pH} \mathrm{4,5,60 \%} \mathrm{em} \mathrm{massa} \mathrm{de} \mathrm{óleo,} \mathrm{5 \%}$ em massa de extrato enzimático, $1000 \mathrm{rpm}$

A hidrólise de óleos e gorduras tem sido catalisada preferencialmente por lipases comerciais de diferentes fontes. No entanto, o extrato bruto de lipase de sementes dormentes de mamona, empregado no presente estudo, apresentou resultados mais atrativos do que lipases disponíveis comercialmente de microrganismos e tecidos animais. ${ }^{34-36}$ Pinheiro et al..$^{34}$ testaram a lipase de Candida rugosa livre e imobilizada por encapsulação em sílica preparada pela técnica sol-gel na hidrólise de três diferentes óleos vegetais como canola, oliva e soja empregando delineamento experimental para a otimização do processo de hidrólise. Máxima porcentagem de hidrólise foi obtida para o óleo de oliva empregando a lipase livre, $12 \%$ após 4 h de reação. Lipases de pâncreas de porco, mamona e $C$. rugosa foram imobilizadas em Celite e empregadas na produção de concentrados de ácido ricinoleico por hidrólise do óleo de mamona. ${ }^{35}$ Dentre os biocatalisadores preparados, elevada concentração de ácido ricinoleico foi obtida com a lipase de pâncreas de porco $(\approx 40 \%$ de hidrólise) após 3 h de reação. A produção de concentrados de ácidos graxos poli-insaturados pela hidrólise do óleo de soja foi realizada empregando diferentes lipases comerciais como Thermomyces lanuginosus, pâncreas de porco e C. rugosa.$^{36}$ Dentre as lipases testadas, a de pâncreas de porco mostrou maior especificidade para os ácidos linoleico e linolênico e máxima porcentagem de hidrólise do óleo (35\%) foi obtida após $6 \mathrm{~h}$ de reação.

\section{CONCLUSÕES}

A hidrólise de óleos vegetais para a produção de concentrados de ácidos graxos foi catalisada por lipase de sementes dormentes de mamona. Esta lipase apresentou maior atividade catalítica na hidrólise de óleos vegetais contendo ácidos graxos poli-insaturados como milho e girassol. Dentre eles, máxima atividade hidrolítica foi detectada para o óleo de milho, selecionado para a produção de concentrados de ácidos graxos e as condições experimentais que maximizam a reação de hidrólise foram determinadas por delineamento experimental. Em condições otimizadas (reações conduzidas a $33{ }^{\circ} \mathrm{C}$ em tampão 
acetato de sódio pH 4,5 (100 mM) contendo 60\% em massa de óleo e $5 \%$ em massa de extrato bruto de sementes sob agitação vigorosa - 1000 rpm), máxima hidrólise do óleo de milho $(84,0 \pm 1,8 \%)$ e girassol $(76,4 \pm 1,3 \%)$ foi detectada após 70 e $80 \mathrm{~min}$ de reação, respectivamente. Este estudo demonstrou que o delineamento experimental foi apropriado para a maximização da reação de hidrólise dos óleos vegetais. A aplicação do extrato enzimático bruto de baixo custo preparado a partir de sementes de dormentes de mamona é uma estratégia economicamente atraente para a produção de concentrados de ácidos graxos, uma importante classe de compostos intermediários para a indústria oleoquímica.

\section{AGRADECIMENTOS}

Os autores agradecem à FAPEMIG (Processo APQ 01527-10), CNPq, CAPES e FINEP pelo suporte financeiro.

\section{REFERÊNCIAS}

1. http://lipidlibrary.aocs.org/market/intro.htm, acessada em Maio 2013.

2. http://www.oilworld.biz/app.php?ista=41a63deb55ef18b5b11a75a16a9 6e35d, acessada em Maio 2013.

3. Lam, M. K.; Tan, K. T.; Lee, K. T.; Mohamed, A. R.; Renewable Sustainable Energy Rev. 2009, 13, 1456.

4. Rooney, D.; Weatherley, L. R.; Process Biochem. 2001, 36, 947.

5. Murty, V. R.; Bhat, J.; Muniswaran, P. K. A.; Biotechnol. Bioprocess Eng. 2002, 7, 57.

6. de Castro, H. F.; Mendes, A. A.; Santos, J. C.; Aguiar, C. L.; Quim. Nova 2004, 27, 146 .

7. Rupani, B.; Kodam, K.; Gadre, R.; Najafpour, G.D.; Eur. J. Lipid Sci. Technol. 2012, 114, 1253.

8. Goswami, D.; Basu, J.K.; De, S.; Chem. Eng. J. 2012, 181-182, 542.

9. Goswami, D.; Basu, J.K.; De, S.; Crit. Rev. Biotechnol. 2013, 33, 81.

10. Chowdhury, A.; Mitra, D.; Biswas, D.; J. Chem. Technol. Biotechnol. 2013, 88, 139.

11. Mendes, A. A.; Oliveira, P. C.; Castro, H. F.; J. Mol. Catal. B: Enzym. 2012, 78, 119 .

12. Hasan, F.; Shah, A. A.; Hameed, A.; Enzyme Microb. Technol. 2006, 39, 235.

13. Sharma, D.; Sharma, B.; Shukla, A. K.; Biotechnology 2011, 10, 23.
14. Villeneuve, P.; Eur. J. Lipid Sci. Technol. 2003, 105, 308.

15. Campillo-Alvarado, G.; Tovar-Miranda, R.; J. Mol. Catal. B: Enzym. 2013, 90, 49 .

16. Barros, M.; Fleuri, L. F.; Macedo, G. A.; Braz. J. Chem. Eng. 2010, 27, 15.

17. Quettier, A. L.; Eastmond, P. J.; Plant Physiol. Biochem. 2009, 47, 485.

18. Gadge, P. P.; Madhikar, S. D.; Yewle, J. N.; Jadhav, U. U.; Chougale, A. D.; Zambare, V. P.; Padul, M. V.; Am. J. Biochem. Biotechnol. 2011, 7, 141.

19. Gu, H.; Jiang, Y.; Zhou, L.; Gao, J.; Energy Environ. Sci. 2011, 4, 1337.

20. Sanders, T. H.; Pattee, H. E.; Lipids 1975, 10, 50.

21. de Sousa, J. S.; Cavalcanti-Oliveira, E. D.; Aranda, D. A. G.; Freire, D. M. G.; J. Mol. Catal. B: Enzym. 2010, 65, 133.

22. Avelar, M. H. M.; Cassimiro, D. M. J.; Santos, K. C.; Domingues, R. C. C.; Castro H. F.; Mendes, A. A.; Ind. Crops Prod. 2013, 44, 452.

23. Ory, L. R.; Angelo, A. J. S.; Altschul, A. A.; J. Lipid Res. 1962, 3, 99.

24. Eastmond, P. J.; J. Biol. Chem. 2004, 279, 45540.

25. Borek, S.; Ratajczak, W.; Ratajczak, L.; Plant Sci. 2006, 170, 441.

26. Soares, C. M. F.; Castro, H. F.; Zanin, G. M.; Moraes, F. F.; Appl. Biochem. Biotechnol. 1999, 77/79, 745.

27. Winayanuwattikun, P.; Kaewpiboon, C.; Piriyakananon, K.; Tantong, S.; Thakernkarnkit, W.; Chulalaksananukul, W.; Yongvanich, T.; Biomass Bioenergy 2008, 32, 1279.

28. Tiss, A.; Carriéri, F.; Douchet, I.; Patkar, S.; Svendsen, A. E.; Verger, R.; Colloids Surf., B 2002, 26, 135.

29. McClements, D. J.; Weiss, J.; Em Bailey's industrial oil and fat products; Shahidi, F., ed.; John Wiley \& Sons Inc.: New York, 2005, cap. 14.

30. Sun, C.; Gunasekaran, S.; Food Hydrocolloids 2009, 23, 165.

31. Moreau, L.; Kim, H. J.; Decker, E. A.; McClements, D. J.; J. Agric. Food Chem. 2003, 51, 6612.

32. Let, M. B.; Jacobsen, C.; Sorensen, A. D.; Meyer, A. S.; J. Agric. Food Chem. 2007, 55, 1777.

33. Saktaweewong, S.; Phinyocheep, P.; Ulmer, C.; Marie, E.; Durand, A.; Inprakhon, P.; J. Mol. Catal. B: Enzym. 2011, 70, 8.

34. Pinheiro, R. C.; Soares, C. M. F.; Castro, H. F.; Moraes, F. F.; Zanin, G. M.; Appl. Biochem. Biotechnol. 2008, 146, 203.

35. Ozcan, H. M.; Sagiroglu, A.; Prep. Biochem. Biotechnol. 2009, 39, 170.

36. Freitas, L.; Bueno, T.; Perez, V. H.; Santos, J. C.; Castro, H. F.; World J. Microbiol. Biotechnol. 2007, 23, 1725. 